\title{
Revising the existing Performance Indicator system for small water supply utilities in Japan
}

\section{$\operatorname{AUTHOR}(S)$ :}

Shinde, Victor Rana; Hirayama, Nagahisa; Mugita, Ai; Itoh, Sadahiko

\section{CITATION:}

Shinde, Victor Rana ... [et al]. Revising the existing Performance Indicator system for small water supply utilities in Japan. Urban Water Journal 2013, 10(6): 377-393

\section{ISSUE DATE:}

2013-12

URL:

http://hdl.handle.net/2433/193046

\section{RIGHT:}

The Version of Record of this manuscript has been published and is available in Urban Water Journal (2013) http://www.tandfonline.com/10.1080/1573062X.2012.739628.; この 論文は出版社版でありません。引用の際には出版社版をご確認ご利用ください。；This is not the published version. Please cite only the published version. 


\title{
Revising the existing Performance Indicator system for small water supply utilities in Japan
}

\author{
Victor Rana Shinde ${ }^{\mathrm{a}^{*}}$, Nagahisa Hirayama ${ }^{\mathrm{b}}$, Ai Mugita ${ }^{\mathrm{c}}$ and Sadahiko Itoh ${ }^{\mathrm{d}}$
}

${ }^{a}$ Urban Management Department, Graduate School of Engineering, Kyoto University, Kyotodaigakukatsura,

Nishikyo, 615-8540, Kyoto, Japan. victorshinde@urban.env.kyoto-u.ac.jp

${ }^{\mathrm{b}}$ Department of Environmental Engineering, Graduate School of Engineering, Kyoto University,

Kyotodaigakukatsura, Nishikyo, 615-8540, Kyoto, Japan. hirayama@hse.gcoe.kyoto-u.ac.jp

' Graduate School of Global Environmental Studies, Kyoto University, Kyotodaigakukatsura, Nishikyo, 6158540 ,Kyoto, Japan.mugita@urban.env.kyoto-u.ac.jp

${ }^{\mathrm{d}}$ Department of Environmental Engineering, Graduate School of Engineering, Kyoto University, Kyotodaigakukatsura, Nishikyo, 615-8540, Kyoto, Japan. itoh@urban.env.kyoto-u.ac.jp

* Corresponding author 


\begin{abstract}
97.5\% of the water utilities in Japan serve less than 50,000 customers, and are called small water utilities. The Performance Indicator system in Japan, used to evaluate the performance of various aspects of the supply system, currently has 137 items, which are too many in number for the small utilities to adopt because of resource and financial constraints. The objective of this study is to, thus, revise the existing PI system to arrive at a reduced, relevant and practical structure that provides enough information to rationally evaluate small water supply systems in Japan. Principal Component Analysis was used to reduce the dimensionality of the original data. The results suggest that only 9 components, consisting of 33 items (called 9-cPIS), are sufficient for evaluating the small water utilities. The effectiveness of the 9-cPIS in benchmarking, evaluating business models, and the planning and management of the water utilities has been discussed further.
\end{abstract}

Keywords: Benchmarking, PDCA cycle, Performance Indicators, Principal Component Analysis Small water utilities, 


\section{Introduction}

The reliable supply of safe and good quality water is the primary objective of any water supply utility. To evaluate and monitor the rate of success, or failure, in meeting this objective, water supply utilities employ a set of Performance Indicators (PIs), quantitative data, which reflect on the performance of various components of the water supply system. The ultimate goal of a PI is not merely statistical evaluation but rather to provide information that aids in decision-making. Hence, the usefulness of PIs does not only pertain to water supply undertakings but also to regional/national planning bodies, regulatory agencies, funding bodies etc. (Algere 2002).

Various international organizations, such as the International Water Association (IWA)(Algere et al. 2006), World Bank (WB 1999), World Health Organization (WHO 2000) and International Benchmarking Network for Water and Sanitation Utilities (IBNET 2005) etc. have proposed different thematic areas of PIs but the main objectives are alike. Table 1 presents the summary of the main components of PIs as described by various organizations.

Table1: Performance Indicator themes recommended by various organizations

\begin{tabular}{|c|c|c|c|}
\hline IWA (2006) & IBNET (2005) & WHO (2000) & WB (1999) \\
\hline $\begin{array}{ll}\text { - } & \text { Water Resources } \\
\text { - } & \text { Personnel } \\
\text { - } & \text { Physical } \\
\text { - } & \text { Operational } \\
\text { - } & \text { Quality of Service } \\
\text { - } & \text { Economic and Financial }\end{array}$ & $\begin{array}{ll}\text { - } & \text { Service Coverage } \\
\text { - } & \text { Water Consumption } \\
& \text { and Production } \\
\text { - } & \text { Non Revenue Water } \\
\text { - } & \text { Metering Practices } \\
\text { - } & \text { Pipe Network } \\
& \text { Performance } \\
\text { - } & \text { Cost and Staffing } \\
\text { - } & \text { Quality of Service } \\
\text { - } & \text { Billing and Collection } \\
\text { - } & \text { Financial Performance } \\
\text { - } & \text { Assets } \\
\text { - } & \text { Pffordability } \\
\end{array}$ & $\begin{array}{ll}\text { - } & \text { User } \\
& \text { Satisfaction } \\
\text { - } & \text { Community } \\
& \text { Management } \\
\text { - } & \text { Financial } \\
\text { - } & \text { Level of } \\
& \text { Service } \\
\text { - } & \text { Materials } \\
\text { - } & \text { Personnel } \\
\text { - } & \text { Equipment } \\
\text { - } & \text { Work Control }\end{array}$ & $\begin{array}{ll}\text { - } & \text { Coverage } \\
\text { - } & \text { Water Consumption } \\
\text { - } & \text { Und Production } \\
& \text { Water } \\
\text { - } & \text { Metering Practices } \\
\text { - } & \text { Pipe Network } \\
& \text { Performance } \\
\text { - } & \text { Cost \& Staffing } \\
\text { - } & \text { Quality of Service } \\
\text { - } & \text { Billing \& } \\
& \text { Collection } \\
\text { - } & \text { Financial } \\
& \text { performance } \\
\text { - } & \text { Capital Investment }\end{array}$ \\
\hline
\end{tabular}

As observed in Table 1, the various organizations have recommended more or less similar themes. The apparent differences noticed are due to the target areas for which the indicator system was developed. For example, the WHO indicator system is primarily for developing countries, where the major concerns for water supply utilities are inefficient services and cost recovery. The IWA themes, on the other hand, cover a wider range of indicators to evaluate every aspect of the system, 
across geographic boundaries, and are considered a major reference in the water industry all over the world (e.g., Kanakoudis and Tsitsifli 2010).

In the recent past there have been studies with an increasing focus on sustainability indicators (Ioris et al. 2008; Palme and Tillman 2008; Duong et al. 2011; Milman and Short 2011; etc.) indicators that integrate the social, environmental and economic aspects of water supply to ensure long-term service. A number of water companies, especially in the developed countries, employ such sustainability indicators. The PIs initiated by Water UK (2009), which includes water utilities in England, Wales, Scotland and Northern Ireland, place high emphasis on climate change and energy, natural resource protection, sustainable consumption \& production apart from the traditional PIs like customer experience, corporate governance and management \& performance. The German Association of Energy and Water Industries (Bundeverband der Energie - und Wasserwirtschaft e. V., Berlin and Brussels - BDEW 2009), compare PIs of major water industries in Germany, in which the thematic focus is on long-term security of supply, sustainable utilization of water resources, high water quality, high customer satisfaction, and economic efficiency. It is difficult to agree on a universal set of indicators and their detailed definitions because the different operating environment each country/region faces can influence comparison. The usefulness of an indicator, and its likelihood to be monitored, varies across countries (World Bank 1999), thereby suggesting that PIs need to be site specific, addressing the needs and concerns of the locality in which the water utility operates.

Small utilities, however, often lack adequate technical, managerial, and financial capacity (USEPA-DWA 2003), and hence the indicator system developed for these utilities may be quite different from that developed for larger utilities. While there have been studies which seek to address various managerial (e.g. Chang et al. 2012; Schwartz and Sanga 2010) and operational (e.g. Ravindran et al. 2009) aspects of small water utilities, very few studies have been carried out on developing PIs for small water utilities. Coulibaly and Rodriguez (2004) developed PIs for small water utilities in Quebac, Canada using historical data, questionnaires and personal observations to establish five groups of variables - agricultural land use, raw water quality, water disinfection, distribution system infrastructure/maintenance and distributed water quality. Sadiq et al. (2010) developed on this study by applying fuzzy analysis (Ordered Weighting Averaging Operators) to integrate the PIs. Makungo et al. (2011), in a slightly different study, used 13 chemical indicators to evaluate the performance of raw and finished water of a small treatment plant in South Africa. However, all these studies aspired to develop a new PI system, as opposed to revising the existing system of indicators, endeavored in this study. 


\section{Background}

After the introduction of the Waterworks Act in 1957, the water supply system in Japan has expanded rapidly, with the population coverage reaching 96.8\% in 2008 from 30\% in 1957. In doing so, approximately 789 multipurpose dams and 1878 single purpose dams were constructed. As a result, a steady supply of approximately 17.8 billion $\mathrm{m}^{3} /$ year has been established for domestic and industrial use. The domestic and industrial sector demand amounts to around 19\% and 15\% of the total demand respectively, while the rest of the demand is taken up by the agricultural sector. According to the Ministry of Land, Infrastructure, Transport and Tourism (MLITT 2008), as of 2004 the combined demand for domestic and industrial use was 28.3 billion $\mathrm{m}^{3}$, of which $75 \%$ is extracted from rivers and dams. Lakes and groundwater contribute to fulfilling the rest of the demand. Although there are five government ministries associated with water resources in Japan, the Ministry of Health, Labor and Welfare (MHLW) is in charge of water supply for domestic use.

As of 2008, there were 16978 waterworks in Japan. Waterworks, as defined by the Japan Water Works Association (JWWA 2008), are water supply systems designed to supply more than 100 people with potable water. $97.5 \%$ of these waterworks have a service population of less than 50000. However in the recent past, there has been an integration of small-scale water supply utilities for better productivity. The water utilities are classified as water supply businesses (managed by municipalities), bulk water supply businesses (managed by prefectures or a group of municipalities), private water supply and private water supply facilities, both of which are small scale suppliers. Japan boasts of excellent tap water quality. The treatment of water varies according to the quality of the source. Approximately $76 \%$ of the utilities use rapid sand filtration, while around $22 \%$ used disinfection without filtration. Since 1995, 22\% of the utilities have adopted advanced treatment processes, which include ozone-GAC treatment coupled with membrane filtration. The average leakage rate for water supply utilities in Japan is around 8\%, which suggests a well-monitored and efficient network (JWWA 2008).

In 2005, guidelines for the management and assessment of a drinking water supply services were developed by the Japan Water Research Center (JWRC), which included a set of performance indicators. Referring to the PIs recommended by various international organizations already mentioned earlier, and discussions with water utility managers, 137 PIs were developed. The PIs are categorized into five themes, namely, safety, stability, sustainability, environment and global cooperation (JWWA 2005). By employing these PIs, drinking water utilities are expected to evaluate 
their own situation objectively, address concerns, arrive at feasible solutions, and consequently, develop their water service activities. Further, the JWWA performs a benchmarking exercise every year with the PI data provided by the utilities. However, there is very poor participation from the utilities. Only 177 utilities in 2004 through 2007, and 199 utilities in 2007 took part in the benchmarking activity. The participation of small water utilities is even more deplorable - 33 out of 199 utilities, in 2007. Additionally, among the 33 utilities that participated in the benchmarking exercise in 2007, only 2 could provide information pertaining to all 137 PIs (Data Source: JWWA 2008).

It is not only the small utilities that find it difficult to evaluate such large number of PIs, larger utilities fare no better. As observed in Fig 1, almost 25\% of the utilities in Japan taking part in the benchmarking activity carried out in 2007, with the 137 PIs proposed by the JWRC, had more than 50 missing entries. Only 4\% of the utilities could provide information for all PIs, suggesting that evaluating and monitoring the current PIs is merely a statistical exercise, with no relevant contribution to planning and management.

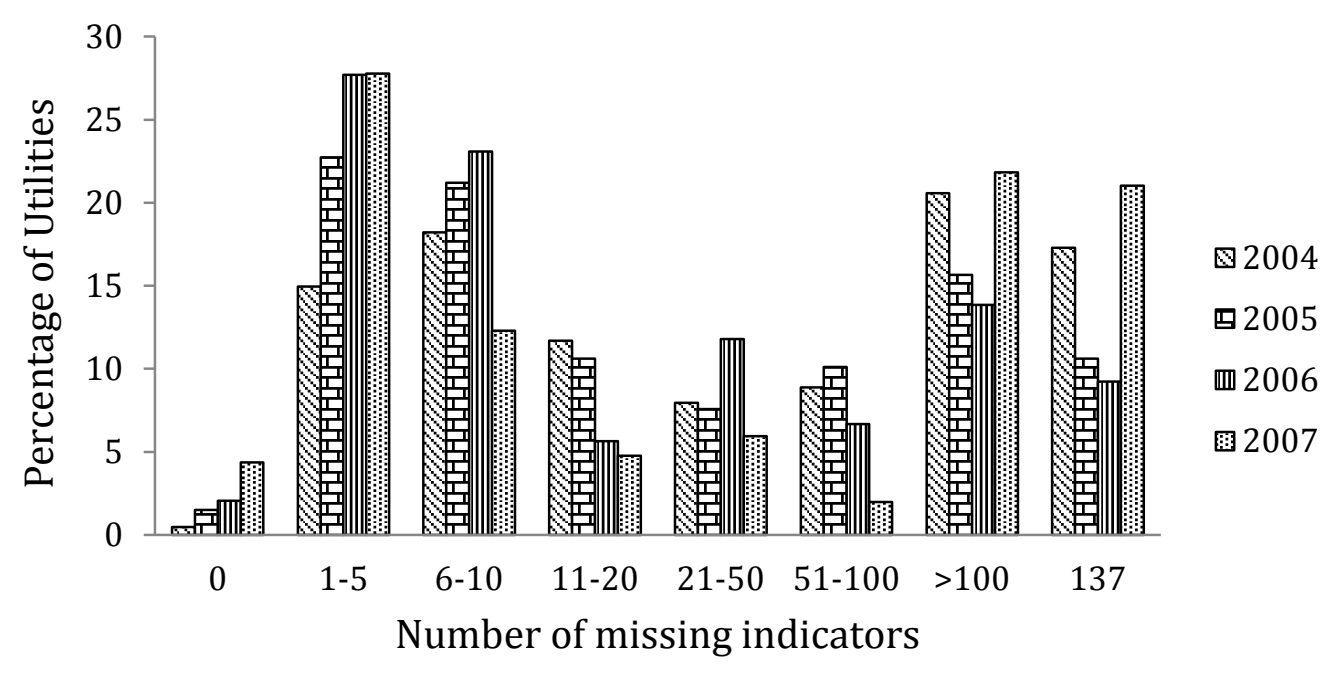

Figure 1: Trend for water supply utilities with incomplete information on PIs

The objective of this study is, thus, to revise the PI system and arrive at a reduced, relevant and practical structure that accounts for enough information required to rationally evaluate small water supply systems in Japan. The study acknowledges that although difficult to evaluate, due to resource and financial constraints, the JWWA indicators have been thoroughly developed with detailed consideration for all aspects of the supply system. Hence, instead of developing a new PI system, this study focuses on reducing the dimensionality in the existing system by selecting the more relevant 
and significant variables. Selecting the appropriate variables can be a delicate task - It can be subjective. Opinions vary across scales of supply, regions and practitioners, and to arrive at a reduced set of indicators merely through discussion would be an onerous task. Hence, to be able to be universally accepted, the choice of indicators should be based on scientific methods and techniques that are beyond debate. This study uses Principal Component Analysis (PCA), a dimension reduction statistical technique, to reduce the PI data set and classify it into smaller, manageable sets, whose suitability is then investigated in context of current and anticipated concerns that need to be addressed by the small water utilities in Japan. Since PCA attempts to also extract the maximum variation from the original data set, the reduced set of indicators respects the JWWA indicator system by retaining as much information as possible from it.

Provided in the next section is a brief description of the study design, which includes identification of the thematic areas of the proposed PI system, data collection, and the general terminology used in PCA. This is followed by the results obtained from the PCA, which culminates in the development of a reduced set of PIs, called 9-component performance indicator system (9cPIS) The applications of the 9-cPIS in the actual planning and management of the small water supply utilities are elaborated subsequently. The paper concludes with the main research findings, states the limitations of the study, and suggests scope for further research.

\section{Methodology}

\subsection{Identifying pertinent concerns to establish thematic areas of proposed PI system}

PIs are usually divided into thematic areas, which are chosen based on the user's needs and managerial targets. To be able to decide upon the thematic areas of the proposed PI system for small water utilities in Japan, to ensure sustainability of the system, it is important to understand and identify the current and future concerns that these utilities are likely to face. These then would lead to the formation of overarching themes under which specific indicators can be included. Accordingly, four pertinent areas of concern were identified.

Primary among these is the demographic trend of the Japanese population. The Ministry of Public Management, Home Affairs, Posts and Telecommunication reports that population in Japan has been on a decreasing trend since the early 2000's with a negative growth rate, and is forecasted to further decrease in the future (Statistics Bureau 2007). With population decrease it is unlikely that Japan will experience water shortage in the future, especially given the nature and quality of the existing facilities. However, the facility utilization rate is likely to reduce, leading to precious 
financial funds being utilized for unnecessary purposes. Oki and Musiake (2009) point out that it will not be easy to maintain the current facilities under decreasing population. The problem is compounded when the population of Japan is classified in different age groups. Approximately 28\% of the population in 2006 was above the age of 60, which is expected to increase to $39 \%$ and $47 \%$ in 2030 and 2055 respectively (Kaneko et al. 2007). A rapidly aging population could lead to lower employee productivity in water utilities, and influx of foreign workers to address the shortfall. This is likely to increase the financial strain on utilities to maintain and operate their systems efficiently.

The second concern is that owing to insufficient revenue collection and increasing depreciation cost, many utilities are incapable of financially sustaining themselves. Additionally, increasing rehabilitation costs for upgrading old facilities further aggravate the problem. Tachikawa (2004) highlighted the fact that the ratio of the amount available for investment to the amount required for rehabilitation is on a decreasing trend, and is expected to reach 1 by 2025 .

Thirdly, climate change is also expected to adversely impact water supply systems in Japan. Based on the GCM20 (A1B) scenarios developed by the MLITT, an average increase in rainfall by a factor of 1.1 is expected across Japan in 2080-2089, compared to 1979-1998. Additionally, due to premature snowmelt, changes in the river flow regimes are a strong possibility. For most parts of the year, the future flow will be more than the current flow, suggesting periods of floods. However, during the crucial period between April and July, when larger amount of irrigation water is required for surface puddling of paddy crops, there will be a drastic reduction of flow in rivers (MLITT 2008), which may very well lead to high competition among water users during this season,

Finally, the consumers' expectation of water quality in Japan has been rising over the years. With progress in technology and ease in obtaining information, consumers are becoming more sensitive to the type and nature of treatment processes used by the utilities. Complaints about chlorinous odor and taste in drinking water are on the rise with consumers becoming more sensitive to changes in water quality (Itoh et al. 2007), leading to increased use of bottled water.

The PI system developed in this study endeavors to identify indicators that are capable of monitoring the affects caused due to these concerns, which is described later in this paper in section 4.1. 


\subsection{Study design}

PCA is a multivariate statistical technique that reduces the dimensionality of a data set containing interrelated variables, while retaining as much as possible of the variation present in the data set. PCA uses eigenvalue decomposition of the correlation/covariance matrix of the data and transforms it into a new set of fewer variables, called Principal Components, which are uncorrelated, and which are ordered so that the first few retain most of the variation present in all of the original data (Kline 1994; Jollife 2002). In developing a performance indicator system, practical studies have pointed out the fact that it is better to consider fewer crucial variables, instead of including all variables because doing so may influence the phenomenon being characterized (Coulibaly and Rodriguez 2004; Ioris et al. 2008). The PCA, in this study, thus seeks to identify the key variables contributing to the respective components. The analysis was performed with IBM SPSS Statistics base 18.0.

For the purpose of this study, the PIs of major water utilities in Japan were considered for analysis. PI data was collected from the JWWA for the years 2004 through 2007, which was available for 177 water utilities from 2004 to 2006, and 199 utilities in 2007. Hence, the initial data set included 730 water utilities (called cases henceforth), over a 4-year period, and 137 PIs (called variables henceforth). However, as pointed out before, there were numerous missing entries. Very few utilities provided information pertaining to certain PIs suggesting that these PIs are either difficult to measure or redundant in the opinion of the managers of those utilities. Similarly some utilities failed to provide information corresponding to most of the PIs implying lack of resources/desire of the utilities to perform the exercise. After omitting the missing data, the number of cases and variables was brought down to 132 and 113 respectively. Since the foundation of this study is based on extracting the maximum variance from the original PIs, efforts were taken to omit as few variables as possible, in the process rendering a small sample size (132), and case to variable ratio (1.2:1). There is no definite rule to ascertain the minimum sample size required to perform PCA and the numerous recommendations made by researchers vary. E.g. some suggest a minimum sample size of 100 (Kline 1979; Gorsuch 1983), or a case to variable ratio ranging from 10:1 (Velicer and Fawa 1998) to 2:1 (Kline 1979). Costello and Osborne (2005) surveyed two year's PsychINFO articles and reported that $14.7 \%$ of the studies used a case to variable ratio of 2:1 or less. Favorable results were obtained with case to variable ratio as less as 1.2:1 (Barret and Kline 1981).

During the analysis, variables with extracted communality less than 0.4 were removed, because such variables will struggle to load on any component. Communality of a variable is the variance in that variable which has been extracted by the components. Thus, if the communality of a variable is 
high, the components account for a bigger proportion of the variable's variance, suggesting that the variable is reflected well in the analysis. Further, results with high communality values for variables are reliable even for small sample sizes (MacCallum et al. 1999). To avoid cross loading, the variables with loadings of 0.5 or higher on more than 1 component were discarded. Loading is defined as the correlation between the variables and the components. High loading variables are understandably crucial but if a variable loads highly on two or more components (cross loading), interpretation of the components becomes difficult and hence these variables should not be included in the analysis, especially if there are other variables loading strongly onto the components (Costello and Osborne 2005). In this study, a variable with loading of more than 0.5 was considered to make a significant contribution to the components. Rule of thumb recommends this value to be 0.32 (Tabachnick and Fidell 2001). However, we have used a higher value since our analysis had many strong loading variables. Components with fewer than three variables were not considered as they are usually weak and unstable (Costello and Osborne 2005). The commonly used Kaiser eigenvalue rule (Kaiser 1960) was used to select the number of principal components for further analysis. According to this rule, only components with eigenvalues greater than one are to be retained for further analysis.

To have a better understanding of the information elucidated by the components, varimax rotation was performed. The goal of rotation is to simplify and clarify the data structure. Rotation cannot improve the basic aspects of the analysis, such as the variance extracted from the items, but merely rearranges the data structure by increasing the loading of variables on one component and reducing it on others. Among the different rotation techniques, varimax rotation is the commonest (Costello and Osborne 2005). Since varimax rotation is orthogonal in nature where the components are not correlated, promax rotation was performed to explore the relationship between components, if any. This is significant in the interpretation of components, and can provide useful insight into identifying whether or not there are common features that contribute to the components. Upon obtaining the final rotated solution, regression equations were developed for each component using the component score coefficients. Component score coefficients are the standardized composite scores of each case on each component.

\section{Results and Discussion}

Table 2 presents the relevant components (or thematic areas), identified from the PCA, which are proposed as pertinent PIs to evaluate the performance of small water supply systems in Japan. The choice of the components were based on the current and future concerns that the water supply utilities 
in Japan are likely to face, discussed in the previous section. The PCA reduced the original set of 113 variables to 9 components consisting of 33 contributing variables (9-cPIS). All contributing variables load strongly onto the respective components, and have high values of extracted communality, thereby mitigating the concerns caused by the small sample size. Also presented in Table 2 is the variance of the original data set extracted by each of the 9 components, indicating a total of $64.9 \%$ variance extracted by the 9 components together. The explanatory notes describing the quantification of the contributing variable are further presented in Table 3.

Table 2: Results of Principal Component Analysis with varimax rotation

\begin{tabular}{|c|c|c|c|c|c|}
\hline Comp & Contributing Variables & Loading & $\begin{array}{l}\text { Extracted } \\
\text { 'communality }\end{array}$ & $\begin{array}{l}\text { Variance } \\
\text { (\%) }\end{array}$ & $\begin{array}{l}\text { Component } \\
\text { Label }\end{array}$ \\
\hline \multirow{4}{*}{1} & Water supply revenue & 0.931 & 0.961 & \multirow{4}{*}{12.70} & \multirow{4}{*}{$\begin{array}{l}\text { Economic Value } \\
\text { of Water }\end{array}$} \\
\hline & Price of water for $\mathrm{HH}$ using up to $20 \mathrm{~m}^{3}$ per month & 0.913 & 0.940 & & \\
\hline & Water production cost & 0.898 & 0.954 & & \\
\hline & Price of water for $\mathrm{HH}$ using up to $10 \mathrm{~m}^{3}$ per month & 0.742 & 0.863 & & \\
\hline \multirow{5}{*}{2} & Staff salary as ratio of total revenue & -0.877 & 0.947 & \multirow{5}{*}{11.26} & \multirow{5}{*}{$\begin{array}{l}\text { Employee } \\
\text { Productivity }\end{array}$} \\
\hline & Water revenue per employee & 0.833 & 0.933 & & \\
\hline & Amount of water supplied per employee & 0.819 & 0.929 & & \\
\hline & Meters per employee & 0.801 & 0.863 & & \\
\hline & Average work experience ratio & -0.744 & 0.885 & & \\
\hline \multirow{4}{*}{3} & Current account balance ratio & 0.935 & 0.955 & \multirow{4}{*}{8.30} & \multirow{4}{*}{$\begin{array}{l}\text { Financial } \\
\text { Sustainability }\end{array}$} \\
\hline & Total balance ratio & 0.920 & 0.951 & & \\
\hline & Revenue to cost ratio of water supply & 0.879 & 0.916 & & \\
\hline & Operating balance ratio & 0.806 & 0.947 & & \\
\hline \multirow{3}{*}{4} & Number of international collaborations & 0.950 & 0.942 & \multirow{3}{*}{7.49} & \multirow{3}{*}{$\begin{array}{l}\text { Adaptive } \\
\text { Management }\end{array}$} \\
\hline & Development expense ratio & 0.871 & 0.817 & & \\
\hline & Requests for information made by consumers & 0.845 & 0.773 & & \\
\hline \multirow{4}{*}{5} & Percentage of outstanding revenue bonds & 0.928 & 0.943 & \multirow{4}{*}{6.84} & \multirow{4}{*}{$\begin{array}{l}\text { Private } \\
\text { Investment }\end{array}$} \\
\hline & Rate of interest for revenue bonds & 0.908 & 0.946 & & \\
\hline & Net worth to total capital & -0.696 & 0.871 & & \\
\hline & Redemption rate of revenue bonds & 0.615 & 0.674 & & \\
\hline \multirow{3}{*}{6} & Greenhouse gases emissions & -0.879 & 0.899 & \multirow{3}{*}{5.13} & \multirow{3}{*}{$\begin{array}{l}\text { Green Water } \\
\text { Supply }\end{array}$} \\
\hline & Power consumption & -0.843 & 0.969 & & \\
\hline & Energy consumption & -0.841 & 0.943 & & \\
\hline \multirow{4}{*}{7} & TOC concentration as ratio of permissible TOC & -0.810 & 0.795 & \multirow{4}{*}{4.93} & \multirow{4}{*}{$\begin{array}{l}\text { Consumer } \\
\text { Satisfaction for } \\
\text { Water Quality }\end{array}$} \\
\hline & THM concentration as ratio of permissible THM & -0.779 & 0.787 & & \\
\hline & Water without chlorinous odor & 0.738 & 0.791 & & \\
\hline & Water without musty odor & 0.607 & 0.640 & & \\
\hline \multirow{3}{*}{8} & Water vehicles ratio & 0.907 & 0.890 & \multirow{3}{*}{4.72} & \multirow{3}{*}{$\begin{array}{l}\text { Emergency } \\
\text { Response Index }\end{array}$} \\
\hline & Pipeline rehabilitation rate & 0.760 & 0.641 & & \\
\hline & Drinking water storage in event of emergency & 0.717 & 0.843 & & \\
\hline
\end{tabular}




\begin{tabular}{|c|c|c|c|c|c|}
\hline & Distribution reservoir seismic facility rate & 0.887 & 0.937 & & Earthquake \\
\hline \multirow[t]{2}{*}{9} & Water treatment plant seismic facility rate & 0.842 & 0.894 & 3.53 & Resistant Water \\
\hline & Pump station seismic facility rate & 0.669 & 0.797 & & Supply \\
\hline
\end{tabular}

Table 3: Description of contributing variables of 9-component Performance Indicator system

\begin{tabular}{|c|c|c|c|}
\hline $\begin{array}{l}\text { Variable } \\
\text { Code }\end{array}$ & Variable & "Unit & Description \\
\hline $\mathrm{EV}_{1}$ & Water supply revenue & Yen $/ \mathrm{m}^{3}$ & $\begin{array}{l}\text { (Revenue earned from water supply/Supply } \\
\text { volume) }\end{array}$ \\
\hline $\mathrm{EV}_{2}$ & Water price for $\mathrm{HH}$ using upto $20 \mathrm{~m}^{3}$ per month & Yen & Self explanatory \\
\hline $\mathrm{EV}_{3}$ & Water production cost & Yen $/ \mathrm{m}^{3}$ & (Total cost of producing water/Supply volume) \\
\hline $\mathrm{EV}_{4}$ & Water price for $\mathrm{HH}$ using upto $10 \mathrm{~m}^{3}$ per month & Yen & Self explanatory \\
\hline $\mathrm{EP}_{1}$ & Staff salary as ratio of total revenue & $\%$ & $\begin{array}{l}\text { (Amount paid as staff salaries/Total revenue) } \\
\text { x100 }\end{array}$ \\
\hline $\mathrm{EP}_{2}$ & Water revenue per employee & 1000Yen/per & (Total revenue/Total employees)/1000 \\
\hline $\mathrm{EP}_{3}$ & Amount of water supplied per employee & $\mathrm{m}^{3} / \mathrm{per}$ & (Supply volume/Total employees) \\
\hline $\mathrm{EP}_{4}$ & Meters per employee & num/per & (Total number of meters/Total employees) \\
\hline $\mathrm{EP}_{5}$ & Average work experience ratio & years/per & $\begin{array}{l}\text { (Total work experience of all employees/Total } \\
\text { employees) }\end{array}$ \\
\hline $\mathrm{FS}_{1}$ & Current account balance ratio & $\%$ & $\begin{array}{l}\text { ((Op income }+ \text { non op income }) /(\text { Op cost }+ \text { Non } \\
\text { op cost })) \text { x100 }\end{array}$ \\
\hline $\mathrm{FS}_{2}$ & Total balance ratio & $\%$ & (Gross revenue/Gross costs) x100 \\
\hline $\mathrm{FS}_{3}$ & Revenue to cost ratio of water supply & $\%$ & $\begin{array}{l}\text { (Unit price of water/Unit cost of production) } \\
\text { X100 }\end{array}$ \\
\hline $\mathrm{FS}_{4}$ & Operating balance ratio & $\%$ & (Op revenue/Op costs) x100 \\
\hline $\mathrm{AM}_{1}$ & Number of international collaborations & num & $\begin{array}{l}\text { Number of interactions with international } \\
\text { agencies }\end{array}$ \\
\hline $\mathrm{AM}_{2}$ & Development expense ratio & $\%$ & (Amount spent on $\mathrm{R} \& \mathrm{D} /$ Total revenue) x100 \\
\hline $\mathrm{AM}_{3}$ & Requests for information made by consumers & num & Self explanatory \\
\hline $\mathrm{PIN}_{1}$ & Percentage of outstanding revenue bonds & $\%$ & $\begin{array}{l}\text { (Capital from non-redeemed bonds/Water } \\
\text { Revenue) x } 100\end{array}$ \\
\hline $\mathrm{PIN}_{2}$ & Rate of interest for revenue bonds & $\%$ & Self explanatory \\
\hline $\mathrm{PIN}_{3}$ & Net worth to total capital & $\%$ & $\begin{array}{l}\text { (Self owned capital/Total liabilities and capital) } \\
\text { x100 }\end{array}$ \\
\hline $\mathrm{PIN}_{4}$ & Redemption rate of revenue bonds & $\%$ & (Bond proceeds/Total revenue) x 100 \\
\hline $\mathrm{GWS}_{1}$ & Greenhouse gases emissions & $\mathrm{gCO}_{2} / \mathrm{m}^{3}$ & ( $\mathrm{CO}_{2}$ emissions/Production volume) \\
\hline $\mathrm{GWS}_{2}$ & Power consumption & $\mathrm{kWH} / \mathrm{m}^{3}$ & (Total power consumption/Production volume) \\
\hline $\mathrm{GWS}_{3}$ & Energy consumption & $\mathrm{MJ} / \mathrm{m}^{3}$ & ((Total energy consumption/Production volume) \\
\hline $\mathrm{CSWQ}_{1}$ & TOC as ratio of standard for TOC & $\%$ & $\begin{array}{l}\text { (Max TOC concentration/Standard for TOC) } \\
\text { x100 }\end{array}$ \\
\hline $\mathrm{CSWQ}_{2}$ & THM as ratio of standard for THM & $\%$ & $\begin{array}{l}\text { (Max THM concentration/Standard for THM) } \\
\text { x100 }\end{array}$ \\
\hline
\end{tabular}




\begin{tabular}{|c|c|c|c|}
\hline $\mathrm{CSWQ}_{3}$ & Water without chlorinous odor & $\%$ & $\begin{array}{l}\text { (1-(Max res chlorine concentration-Standard for } \\
\text { residual chlorine)/ Standard for residual chlorine) } \\
\text { x100 }\end{array}$ \\
\hline $\mathrm{CSWQ}_{4}$ & Water without musty odor & $\%$ & $\begin{array}{l}\text { ((1-Max Geosim concentration/Standard for } \\
\text { Geosim)+(1-Max 2-MIB } \\
\text { concentration/Standard for 2-MIB))/2 x100 }\end{array}$ \\
\hline $\mathrm{ERI}_{1}$ & Water vehicles ratio & num/1000 per & (Number of vehicles/Population served) x 1000 \\
\hline $\mathrm{ERI}_{2}$ & Pipeline rehabilitation rate & $\%$ & $\begin{array}{l}\text { (Length of rehab pipeline/Total length of } \\
\text { pipeline) x } 100\end{array}$ \\
\hline $\mathrm{ERI}_{3}$ & Drinking water storage in event of emergency & L/per & $\begin{array}{l}\text { ((1/2(Total water supply)+(Capacity of } \\
\text { emergency storage tanks)/Population served) x } \\
100\end{array}$ \\
\hline ERS $_{1}$ & Distribution reservoir seismic facility rate & $\%$ & $\begin{array}{l}\text { (Capacity of reservoirs with anti-seismic } \\
\text { design/Total Capacity) x } 100\end{array}$ \\
\hline $\mathrm{ERS}_{2}$ & Water treatment plant seismic facility rate & $\%$ & $\begin{array}{l}\text { (Capacity of plants with anti-seismic } \\
\text { design/Total Capacity) x } 100\end{array}$ \\
\hline $\mathrm{ERS}_{3}$ & Pump station seismic facility rate & $\%$ & $\begin{array}{l}\text { (Capacity of stations with anti-seismic } \\
\text { design/Total Capacity) x } 100\end{array}$ \\
\hline
\end{tabular}

The results obtained from promax rotation were identical to the ones obtained with varimax rotation - the same 9 components were extracted, and the same variables loaded onto the components with promax rotation as with those of varimax rotation, albeit with different component scores. Additionally, as seen in Table 4, there is no relevant correlation between the components suggesting that the components more or less exhibit an orthogonal trend. Hence the results with varimax rotation have been considered for further analysis.

Table 4: Component correlation using promax rotation for Performance Indicator analysis

\begin{tabular}{|c|c|c|c|c|c|c|c|c|c|}
\hline Component & 1 & 2 & 3 & 4 & 5 & 6 & 7 & 8 & 9 \\
\hline 1 & 1 & -0.05 & 0.14 & -0.14 & 0.11 & 0.12 & -0.20 & -0.08 & 0.10 \\
\hline 2 & & 1 & 0.03 & -0.07 & -0.12 & -0.06 & 0 & 0.02 & 0 \\
\hline 3 & & & 1 & 0.06 & 0.13 & 0.21 & -0.09 & -0.09 & 0.03 \\
\hline 4 & & & & 1 & -0.26 & -0.07 & 0.08 & -0.13 & 0.01 \\
\hline 5 & & & & & 1 & 0.04 & -0.19 & 0.04 & 0.05 \\
\hline 6 & & & & & & 1 & 0.14 & -0.01 & -0.11 \\
\hline 7 & & & & & & & 1 & -0.02 & -0.01 \\
\hline 8 & & & & & & & & 1 & -0.02 \\
\hline 9 & & & & & & & & & 1 \\
\hline
\end{tabular}




\subsection{Thematic areas and relevance of the proposed PI system}

Based on the PCA results, the first component has been named "Economic Value of Water", which supports the notion outlined in Dublin Principle 4 (UNCED 1992) that "water has an economic value in all its competing uses and should be recognized as an economic good”. Water supplied by public agencies is usually priced at its average delivery cost rather than its value to producers. As a result water is rarely priced at its marginal value (Young 2005). This is all the more true in Japan where the water charges account for only $0.5-0.7 \%$ of an average household's income (JWWA 2008). Further, the average unit price of water and sanitation in Japan in 2008 was $\$ 1.85 / \mathrm{m}^{3}$, which is markedly lower than other OECD countries (Organization for Economic Cooperation and Development) like Australia (\$2.44), Sweden (\$3.59), France (\$3.74), England and Wales (\$3.82), Finland (\$.4.41), Germany (\$5.72) and Denmark (\$6.70) (OECD 2010). A fair Economic Value of Water leads to making informed choices about the use, conservation and allocation of water. Water having an appropriate price will give a clear signal to the users that water is indeed a scarce good that should be used sparingly (Zaag and Savenije 2006). The 'water supply revenue' and 'water production cost' are two variables that understandably have a large bearing on the Economic Value of Water, as observed in Table 2. Because Japan has a stepped water tariff system, in which the unit price for higher consumption is more than that for lower consumption, it can thus be inferred that the 'water price for households using up to $20 \mathrm{~m}^{3} /$ month' is more likely to enhance Economic Value of Water than the 'water price for households using up to $10 \mathrm{~m}^{3} / \mathrm{month}$ ', as seen by the magnitude of variable loadings in Table 2. With variation in the amount and pattern of rainfall in the future, the water production cost is very likely to increase, thereby affecting the other contributing variables, and hence making Economic Value of Water an important PI to assess the performance of the system.

“Employee Productivity”, the second component, is an important PI in context of Japan's demographical pattern. The population of Japan has been following a decreasing trend and is projected to decrease to under 100 Million in 2046 from 127.3 Million in 2007 (Kaneko et al. 2007), which will result in reduced water production. Under the circumstances, it will be important for utilities to arrive at an appropriate level of work output from its employees ('water revenue per employee', 'amount of water supplied per unit staff' and 'meters per unit staff'), without compromising on the efficiency of supply. Additionally, because Japan has a rapidly aging population, the strength of the work force will reduce. This may lead to increased salaries and hiring of foreign personnel, which usually results in a higher proportion of the revenue spent on remuneration, thereby causing the Employee Productivity to drop ('staff salary as ratio of total revenue'), as indicated by the negative loading of this variable in Table 2. An aging population will also result in older 
employees with more number of years as work experience ('average work experience ratio'). Because the salaries in Japan are usually based on seniority, it follows that that more revenue will be spent on salaries, resulting in reduced Employee Productivity (Negative loading of this variable in Table 2).

"Financial Sustainability" of a project, as defined by the ADB (1997), refers to a condition that "the project will have sufficient funds to meet all its resource and financing obligations, whether these funds come from user charges or budget sources; will provide sufficient incentive to maintain the participation of all project participants; and will be able to respond to adverse changes in financial conditions". Hence, to achieve Financial Sustainability, this essentially means that the unit price of supplied water should exceed, or at least equal, the unit production cost ('revenue to cost ratio of water supply'). Further the revenues generated should at least recover cost incurred. For a typical water supply utility in Japan, there are three components of revenue and corresponding costs operating revenue (revenue received through water bills only), non-operating revenue (revenues generated from sales of bonds etc.) and acquisition revenue (revenues generated by sales of land or assets). Accordingly, to ensure Financial Sustainability, it is important for utilities to maximize the 'operating balance', 'current account balance' and 'total balance ratios', respectively. The uncertain nature of water availability and quality in the future are likely to have profound implications on Financial Sustainability of water supply utilities generally, small utilities in particular.

For water supply utilities, change is inevitable - which could be in the form of water availability, water quality, consumer perception, policy formulation etc. However, it is the uncertainty of change that is a major concern for planners. To cope with uncertainty, there is a need for water supply utilities to continuously monitor these changes and arrive at feasible alternatives to counter potential ill effects brought about by the changes. “Adaptive Management” is an approach that seeks to provide flexible and responsive management approaches over time (Gregory et al. 2006). For Adaptive Management to succeed there must be an awareness of the problem which can be comprehended from 'requests for information made by consumers', mechanisms and funds for research to address the problem ('development expense ratio’) and exchange of scientific ideas and experiences with like-minded partners ('number of international collaborations').

"Private Investment” in water supply utilities seeks to address the involvement of the private sector in water supply. A toned down form of the 'Public-Private-Partnership (PPP)', Private Investment not only serves as an additional source of income for the utilities but also projects a 
confident and reliable look to the stakeholders. Since private investors invariably look for high rate of returns, this will encourage the water supply utilities to have efficient systems and better management, capable of delivering quality product. This indicator is of particular significance for small-scale utilities in Japan to improve on the debilitated state of existing finances. The amount of private investment made in a franchise can be gauged by monitoring the 'percentage of outstanding revenue bonds' and the 'redemption rate of revenue bonds'. The 'rate of interest of revenue bonds' will serve as an incitement for private investors. The 'net worth to total capital' measures the indigenous stake of equity of the water supply utility, and varies inversely with the amount of Private Investment, thereby justifying its negative loading in Table 2.

In context of climate change, developing a "Green Water Supply" system is an important objective for water supply utilities, especially so in Japan which has committed to reducing the Greenhouse gases (GHG) emissions by 25\% in 2025 from the 1990 base year. Although the water sector contributes to less than 1\% of the nation's total GHG emissions, a Green Water Supply with reduced 'power consumption', and 'energy consumption' thereby leading to reduced 'GHG emissions', will set an example for other sectors to provide environmentally friendly services. The three contributing variables have an inverse relationship with the Green Water Supply, thereby explaining their negative loadings in Table 2.

The Intergovernmental Panel on Climate Change (IPCC) forecast warmer and wetter days for Japan in the future (Bates et al. 2008). This has a direct repercussion on the water quality in terms of microbial growth, pollutant concentration etc., which could well entail a change in the treatment technology. Although the quality of drinking water in Japan is comparable with the best in the world, complaints due to disinfection by products (Trihalomethanes-THM), Cryptosporidium, chlorinous odor etc. are still rampant (Itoh et al. 2006). Hence as indicated by the PCA results, to ensure “Consumer Satisfaction for Water Quality” in Japan, the 'THM' and 'total organic carbon (TOC) concentrations as ratios of standard levels' will have to be minimum, as indicated by the negative loadings of these variables in Table 2, while water relatively 'free of chlorinous and musty odors' will enhance the Consumer Satisfaction for Water Quality.

With an expected increase in the variability of precipitation pattern, an effect of climate change, the occurrences of flood and droughts become more pronounced. An effective "Emergency Response Index” will, thus, be required to ensure safe and equitable distribution of treated water. 'drinking water storage in event of disaster' and 'emergency water vehicles ratio' are among the important 
variables contributing to this PI component. Oki and Musaike (2009) point out that as of 2005, close to $11,000 \mathrm{~km}$ of the existing pipelines were installed more than 40 years ago. Hence having a satisfactory 'pipeline rehabilitation rate' would improve the efficiency of the supply systems, which could prove very useful in periods of reduced water supply.

Japan is situated on the Pacific ring of fire, at the juncture of three tectonic plates, where earthquakes are a common phenomenon, hence highlighting the importance of having an "Earthquake Resistant Water Supply Network”. The PCA indicates that 'distribution reservoir, treatment plant and pump stations seismic facilities rates' are the more crucial variables affecting this component. Although not relevant from a climate/ socioeconomic change point of view, this component is significant in Japan's context, reinforcing the notion mentioned earlier that the PI system needs to be site specific.

The 9-cPIS provides the small utilities in Japan with a condensed set of PIs, which is more manageable and practical. The indicator system while comparable with PI systems recommended by other agencies like the IWA, IBNET etc. (Refer Table 1), yet evaluates aspects which are specific to the Japanese water supply context.

Based on the discussion made above, Figure 2 shows the relevance of the 9-cPIS in context of the Japanese water supply by demonstrating its ability to address the various current and future concerns faced by the water supply sector as highlighted previously in section 3.1. Accordingly it is seen that the concerns due to decreasing population, which may very well result in a reduced workforce, is monitored by the Employee Productivity and Private Investment components. Whether or not small water utilities are capable of financially sustaining themselves is monitored with the Financial Sustainability and Economic Value of Water components, while the Earthquake Resistant Supply component evaluates how much investment has been made in earthquake resistant measures, which reflect on the overall financial state of the utility. The various effects of climate change on the supply systems, and the system's ability to adapt, are monitored with the help of the Adaptive Management, Green Water Supply and Emergency Response Index components. The Consumer Satisfaction for Water Quality component measures the rising expectation of the quality of drinking water that consumers are beginning to have. It is, thus, apparent that the 9-cPIS is capable of monitoring the major concerns that small water utilities in Japan are likely to face. 


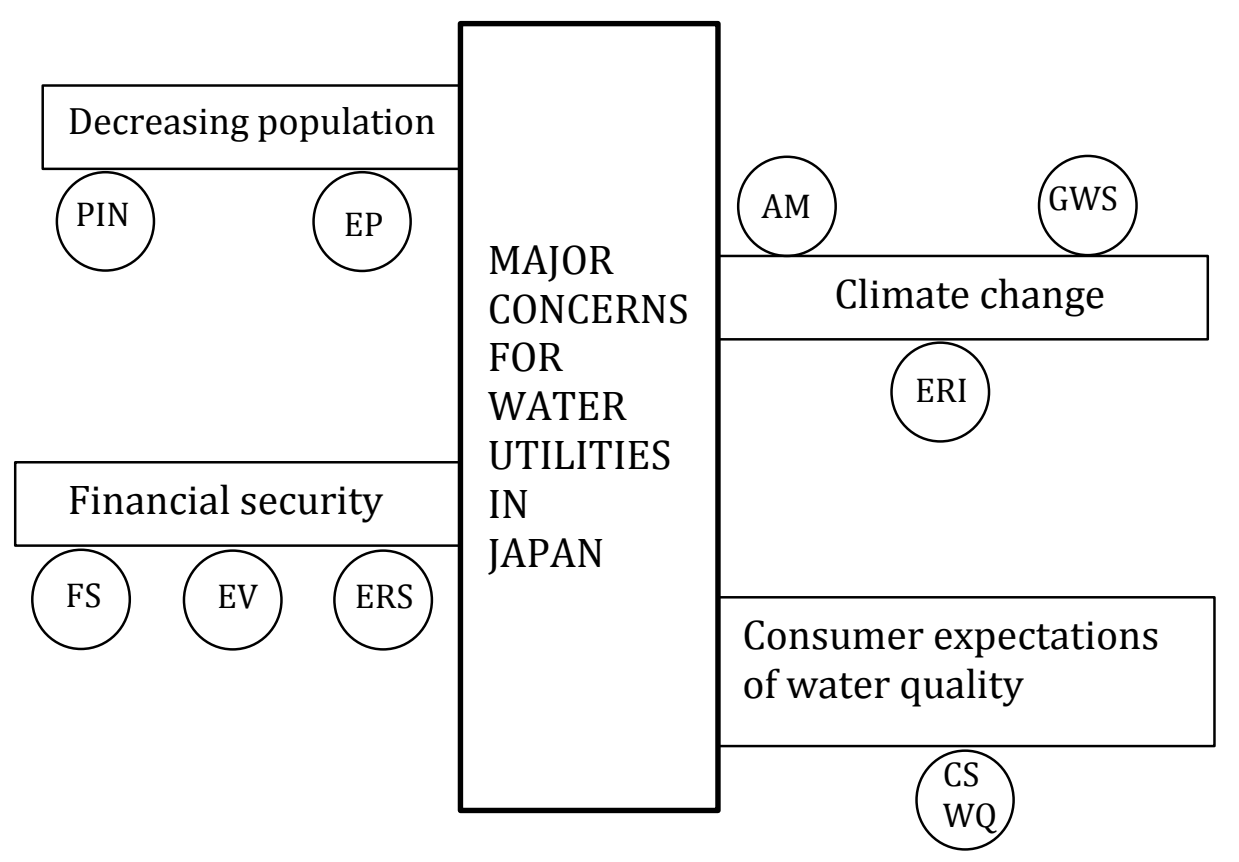

EV: Economic Value of Water; EP: Employee Productivity; FS: Financial Sustainability; AM: Adaptive Management; PIN: Private Investment; GWS: Green Water Supply; CSWQ: Consumer Satisfaction for Water Quality; ERI: Emergency Response Index; ERS: Earthquake Resistant Supply

Figure 2: Relevance of the 9-cPIS for Japanese water utilities

\subsection{Usefulness of the 9-cPIS}

\subsubsection{Ease of use}

It was shown earlier in Figure 1 that less than 5\% of the utilities which took part in the benchmarking exercise in 2007 could provide information for all the 137 original PIs. Based on the data collected from the JWWA, for the same year, Figure 3 shows the number of utilities that have provided information corresponding to the 9 components of the 9-cPIS. Accordingly it is seen that more than $63 \%$ of the utilities, which took part in the benchmarking exercise in 2007 provided data for all the components of the 9-cPIS. Data availability for the Earthquake Resistant Water Supply component was the least, with $63 \%$ of the utilities providing the relevant data, while maximum data was available for the Financial Sustainability component, with $73 \%$ of the utilities providing the relevant data. It can be thus seen that, there is more data available for the 9-cPIS compared to the original PI system, suggesting that use of the 9-cPIS can very well result in wider participation for benchmarking. 


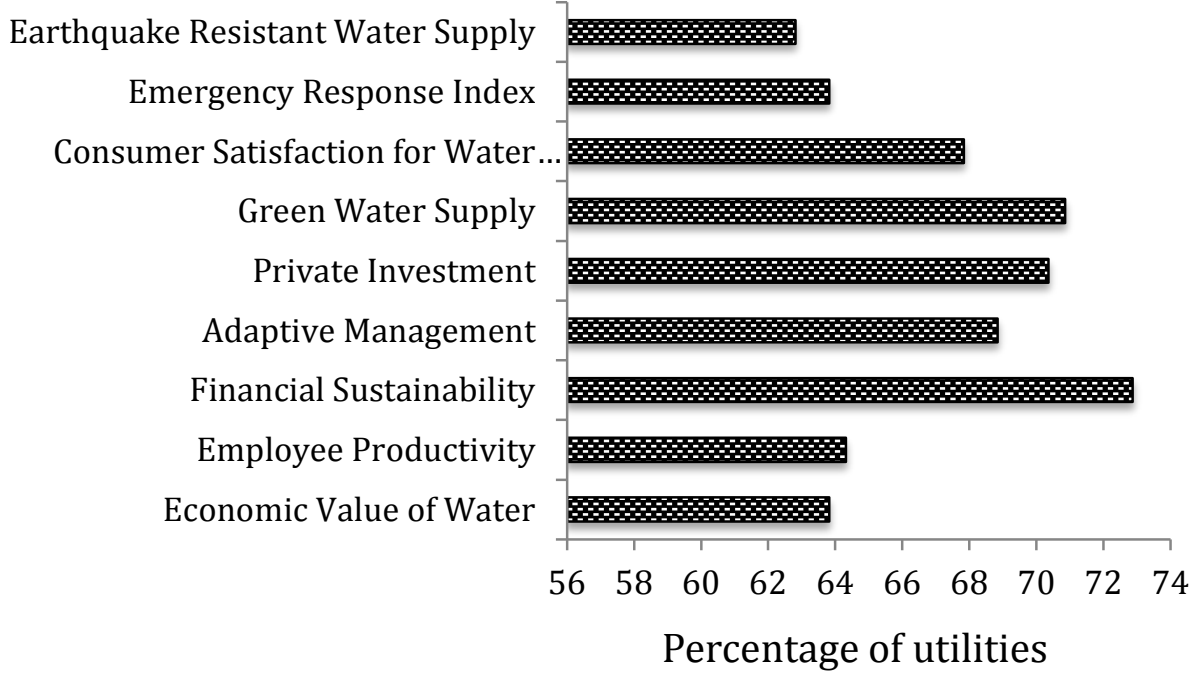

Figure 3: Data availability for the components of the 9-cPIS in 2007

Further, the use of the 9-cPIS is cost effective. Out of the 9 components, the measurement of only the variables of the Consumer Satisfaction of Water Quality component requires specialized equipment and technology, to measure the concentrations of THMs, TOC, residual chlorine, Geosmin and 2-MIB in finished water. However, all these items are already included in the Japanese Water Standards via the revised Water Supply Act of 2003, which makes it mandatory for utilities to make this information available to the public at all times. Currently, only the larger utilities have the facilities and equipment to test the various parameters of drinking water. The small water utilities collect water samples and send them to the Water Quality Monitoring Centers of the nearest large utility, for a stipulated fee. Hence, the small water utilities will not incur any additional cost on account of this component of the 9-cPIS. For the remaining components of the 9-cPIS, collecting the information pertaining to the corresponding PIs merely involves good bookkeeping and maintaining records of operation activities, which is not financially taxing.

\subsubsection{Comparison with other performance measurement systems}

Among the various performance measurement systems used across different businesses, the Balanced Score Card (BSC), developed by Kaplan and Norton (1992), has been employed by many water utilities worldwide (e.g. Vewin 2007, Tynan and Kingdon, 2005). The BSC looks at an organization’s achievements from four perspectives - Financial, Internal business, customer, and innovation \& learning. The financial perspective reflects on whether or not the organization is profitable, purely in monetary terms. The internal business perspective focuses on the business processes that have the greatest impact on the end product. The customer perspective addresses the issue of customer 
satisfaction, which results from quality products supplied at a reasonable price. The innovation \& learning perspective involves activities related to continuous improvement in the organization's ability to deliver the product in a better and more efficient way. Table 5 presents the application of the 9-cPIS in the BSC framework, details of which are discussed hereafter.

Table 5: Application of the 9-cPIS in the Balanced Score Card framework

\begin{tabular}{lll}
\hline \hline Perspective & Major items to be measured & Performance Indicators in the 9-cPIS \\
\hline Financial & Revenues and Costs & $\mathrm{FS}_{1}, \mathrm{FS}_{2}, \mathrm{FS}_{3}, \mathrm{FS}_{4}$ \\
& Private sector investment & $\mathrm{PIN}_{1}, \mathrm{PIN}_{4}$ \\
\hline Internal business & Water Production & $\mathrm{EP}_{3}$ \\
& Labor output & $\mathrm{EP}_{2}, \mathrm{EP}_{4}$ \\
& Safety measures & $\mathrm{ERS}_{1}, \mathrm{ERS}_{2}, \mathrm{ERS}_{3}$ \\
\hline Customer & Water quality & $\mathrm{CSWQ}_{1}, \mathrm{CSWQ}_{2}, \mathrm{CSWQ}_{3}, \mathrm{CSWQ}_{4}$ \\
& Water price & $\mathrm{EV}_{2}, \mathrm{EV}_{4}$ \\
& Reliability of service & $\mathrm{ER}_{1}, \mathrm{ER}_{2}, \mathrm{ER}_{3}$ \\
\hline Learning and & Research and Development & $\mathrm{AM}_{2}$ \\
Innovation & Training & $\mathrm{AM}_{1}$ \\
\hline Environmental & Energy use & $\mathrm{GWS}_{1}, \mathrm{GWS}_{2}, \mathrm{GWS}_{3}$ \\
\hline
\end{tabular}

From a water utility's point of view, the financial perspective can be measured in terms of the various kinds of revenues and expenditures (operating, non operating, acquisition etc.), and the extent of private sector investment. From the discussion provided earlier in section 4.1, it is clear that contributing variables of two components of the 9-cPIS - Financial Sustainability and Private Investment - are capable of measuring this perspective of the BSC. The internal business perspective for a water utility would ideally involve measurements related to the labor output, units of production, safety etc. Two contributing variables of the Employee Productivity component of the 9-cPIS, 'water revenue per employee' and meters per unit staff, account for the labor turnover, while the water production can be estimated from the 'amount of water supplied per unit staff' variable of the same component. To ensure safety of both employees and assets, the Earthquake Resistant Supply component of the 9-cPIS is suitable as an evaluation parameter. The customer perspective for a water utility normally includes three main issues: water quality, water price and reliability of supply. The water quality aspect can be evaluated with the contributing variables of the Consumer Satisfaction for Water Quality, while the ‘price for HH using up to 10 and $20 \mathrm{~m}^{3} / \mathrm{month}^{\prime}$ variables of the Economic Value of Water component of the 9-CPIS are suitable for measuring the water price aspect from a consumer's point of view. 96.8\% of Japan's population receives continuous (24-hour) water supply, and it is unlikely that this will change significantly. Hence, coverage and reliability are not notable issues under normal circumstances. However, in times of emergencies like floods, earthquakes etc., reliability of services become crucial. The contributing variables of the Emergency Response Index 
component of the 9-cPIS are appropriate to measure this aspect. The innovation \& learning perspective for a water utility will include tangible measurements of the extent of Research and Development carried out, and interactions with other utilities for knowledge sharing and capacity building. The ‘development expense ratio' and 'number of international collaborations' variables of the Adaptive Management component are apt for measuring these aspects. To targeting sustainability of supply, researchers have recommended the expansion of the original BSC framework to include an 'environmental perspective' as well (Blokland 2010). Accordingly, the major item to be measured would be the energy use, which can be measured by the contributing variables of the Green Water Supply component of the 9-cPIS.

\subsubsection{Benchmarking}

An important product of any PI system is benchmarking. Benchmarking compares the performance of different water supply utilities, within or across countries, thereby encouraging healthy competition among companies to provide efficient and reliable services, which are financially beneficial. The nine components of the PI system developed in this study were quantified by developing regression equations using the component score coefficients, resulting from the PCA. These are presented in Equations (1) through (9).

$$
\begin{aligned}
& E V=\left(0.264 E V_{1}\right)+\left(0.241 E V_{2}\right)+\left(0.253 E V_{3}\right)+\left(0.152 E V_{4}\right) \\
& E P=\left(-0.256 E P_{1}\right)+\left(0.244 E P_{2}\right)+\left(0.206 E P_{3}\right)+\left(0.201 E P_{4}\right)+\left(-0187 E P_{5}\right) \\
& F S=\left(0.280 F S_{1}\right)+\left(0.275 F S_{2}\right)+\left(0.232 F S_{3}\right)+\left(0.207 F S_{4}\right) . \\
& A M=\left(0.285 A M_{1}\right)+\left(0.252 A M_{2}\right)+\left(0.247 A M_{3}\right) . \\
& P I N=\left(0.341 P^{P I N}\right)+\left(0.313 P_{1} I N_{2}\right)+\left(-0.232 P I N_{3}\right)+\left(0.199 P^{2} N_{4}\right) \\
& G W S=\left(-0.366 G W S_{1}\right)+\left(-0.319 G W S_{2}\right)+\left(-0.323 G W S_{3}\right) . \\
& C S W Q=\left(-0.315 C S W Q_{1}\right)+\left(-0.281 C S W Q_{2}\right)+\left(0.288 C S W Q_{3}\right)+\left(0.263 C S W Q_{4}\right) \\
& E R I=\left(0.335 E R I_{1}\right)+\left(0.284 E R I_{2}\right)+\left(0.286 X_{E R I_{3}}\right) . \\
& E R S=\left(0.351 E R S_{1}\right)+\left(0.334 E R S_{2}\right)+\left(0.271 E R S_{3}\right)
\end{aligned}
$$

where,

EV: Economic Value of Water; EP: Employee Productivity; FS: Financial Sustainability; AM: Adaptive Management; PIN: Private Investment; GWS: Green Water Supply; CSWQ: Consumer Satisfaction for Water Quality; ERI: Emergency Response Index

Refer indicator codes in Table 3 for details of variables

The coefficients in Equations 1 through 9 correspond to the component scores coefficients, which are an outcome of the PCA. The subscripts in the equations correspond to contributing 
variables of the components, details of which can be revisited in Table 3. The developed equations result in an index for each component whose magnitudes are proposed for benchmarking. Such an index is particularly useful in encouraging the participation of those utilities that are reluctant in divulging details of financial or personnel information (a common condition in Japan), which is usually required in traditional benchmarking. An additional development would be to standardize the magnitudes of the components of the 9-cPIS in a certain range, so as to facilitate the comparisons between utilities. Since only the standardized indices of different utilities would be compared, there is a strong possibility of broader participation. Also, because the 9-cPIS contains fewer variables compared to the original set, there is a strong possibility of more participation from the small water utilities.

\subsubsection{Diversity of the 9-cPIS}

To be considered for adoption at a national scale, a good PI system should be diverse enough to be able to evaluate the performance of the various divisions of the supply system - Operations, Finances, Personnel, Resources etc. These divisions of the supply system, and their interactions, can be represented in the form of a business model. The aim of this section is not to develop a new business model but rather show the application of the 9-cPIS in evaluating the model. Hence, the model proposed for this study uses the basic framework developed by Osterwalder and Pigneur (2010), shown in Figure 4. This study has adapted the model for water supply utilities in Japan.

The business model canvass entails 8 elements. The 'key partners' element refers to the stakeholders involved in the water supply business. Since over 95\% of the water utilities in Japan are under the public sector, prefectural and municipal governments are the major partners. Private investors and members of the community are the other partners. The Private Investment component of the 9-cPIS can evaluate this aspect of the business model.

The 'key activities' for a typical small water supply utility in Japan includes intake, treatment, distribution and effluent. The intake and distribution activities are mainly concerned with the quantity of water available for supply. Since the current penetration rate is above $97 \%$, water shortage is presently not a concern (JWWA 2008) and given the nature of Japan's supply system and decreasing population trend, water shortage is not likely to be a cause of concern. Hence the more pertinent indicators with respect to this element of the business model can be limited to Consumer Satisfaction for Water Quality and Employee Productivity.

For any water supply utility, water, employees and assets form the core of the 'key resources'. In light of changing climate and socioeconomic conditions, these resources are likely to be the Drivers 
of Change, which would affect water supply systems and the subsequent management of water supply. The Employee Productivity and Financial Sustainability components address this element of the business model.

\begin{tabular}{|c|c|c|c|}
\hline $\begin{array}{l}\text { Key Partners } \\
\text { - } \text { Prefectural government } \\
\text { - } \text { Municipal government } \\
\text { - Investors } \\
\text { PIN }\end{array}$ & $\begin{array}{l}\text { Key Activities } \\
\text { Key Resources } \\
\text { - Water } \\
\text { - Employees } \\
\text { - Assets }\end{array}$ & $\begin{array}{l}\text { Creating value } \\
\text { - Water Quality } \\
\text { - Environment } \\
\text { Conscious }\end{array}$ & $\begin{array}{l}\text { Customer relationship } \\
\text { - Helpline } \\
\text { - Complaints division }\end{array}$ \\
\hline $\begin{array}{l}\text { Cost Structure } \\
\text { - Operating } \\
\text { - } \text { Redemption } \\
\text { - Acquisition }\end{array}$ & & \multicolumn{2}{|c|}{$\begin{array}{l}\text { Revenue Stream } \\
\text { - Water fees } \\
\text { - Investment } \\
\text { - Asset liquidity }\end{array}$} \\
\hline
\end{tabular}

Figure 4: Business model canvass for Japanese water supply utilities evaluated by 9-cPIS

The 'value proposition' element of the business model refers to the appeal of the product and its special characteristics. Reliable supply of good quality water and an environmentally friendly supply system add to the appeal of produced water. The Green Water Supply and Consumer Satisfaction for Water Quality components can evaluate the value proposition component of the business model. Further, having a strong Emergency Response Index and sound Earthquake Resistant Supply will enhance the reputation of the water supply utility and garner more trust from consumers.

The ‘customer relationship' element is the interaction of the customers with the water supply utilities. These interactions could be in the form of meetings, questionnaires, forums etc. However, in this context the interaction that directly leads to problem solving has been considered as customer relationship. This can be gauged by the Adaptive Management component, which takes into account customer-utility interaction to dynamically solve problems. 
The 'cost Structure' and 'revenue streams' elements form the financial array of the business model. While operation, redemption and acquisition contribute to the expenses, water fees, asset liquidity and investment make up the revenue. The Financial Sustainability and Economic Value components of the 9-cPIS are capable of evaluating these elements of the business model.

\subsubsection{Operating the PDCA cycle for planning and management}

With a sound and effective performance indicator system in place, water supply utilities can dynamically work towards attaining high efficiency and the desired quality of service (Algere et al. 2006). The information elucidated from the evaluation PIs should ultimately help in decision making, thereby playing an important role in the planning and management of water supply utilities. This section endeavors to explain the potential application of the 9-cPIS in the PDCA (Plan-Do-CheckAct) cycle for small water supply utilities in Japan.

The PDCA cycle is an iterative, four-step problem solving/planning process used in business process improvement. The components of the PDCA cycle are - Plan (To prepare a framework to address current and anticipated concerns, and suggest potential remedial/preventive solutions), Do (To check feasible solutions at small scale level), Check (To assess the performance of the proposed solutions against a set of indicators) and Act (To implement most feasible solution in real time). In line with the iterative and dynamic nature of the cycle, further fine-tuning of the system and identification of new concerns are carried out, and the cycle repeated (Deming 1986).

The 9-cPIS is primarily concerned with the 'Check' stage of the PDCA cycle, and addresses the current and future concerns that water supply utilities in Japan are likely to face. The Emergency Response Index indicator evaluates the ability of the system to cope with expected changes in water quantity (floods and draughts). Consumer Satisfaction for Water Quality evaluates the quality of supplied water in terms of consumer satisfaction (effects of increased turbidity, pollutant concentration, microbial growth etc.) while the Adaptive Management indicator throws light on the ability of the utility to dynamically cope up with concerns (Research and Development). Green Water Supply monitors the environmentally friendly aspect of the system (GHG emissions, energy consumption etc.). Financial Sustainability, Economic Value of Water and Private Investment monitor the financial aspects of the utilities while the Employee Productivity indicator monitor the effect of decreasing service population. Figure 5 explains the potential application of the 9-cPIS in the PDCA cycle. 
Model feasible solutions (Supply system + Drivers of change + Proposed solution)
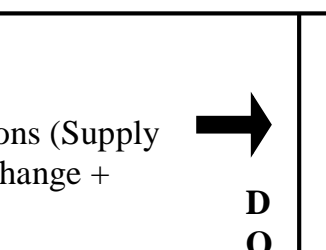

C

H Test feasible solutions against

E 9-cPIS

\begin{tabular}{l|ll}
$\mathbf{D}$ & $\mathbf{C}$ & (E.g. GWS, CSWQ)
\end{tabular}

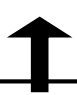

Identify potential feasible solutions to address the problem (E.g. Change in treatment technology, Increased use of renewable energy etc.)

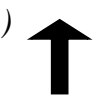

- Set acceptable standards

- Establish project objectives

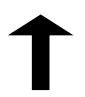

Quantify detailed expected impact on supply system (Simulation modeling)

Estimate preliminary impact on supply system (E.g. Time series analysis, expert opinion, interaction with international partners)

Identify concerns/Drivers of change (E.g. Change in water quality, quantity, GHG emissions)
P
L
A
$\mathbf{N}$
$\mathbf{N}$
$\mathbf{I}$
$\mathbf{N}$
$\mathbf{G}$
$\mathbf{P}$
$\mathbf{H}$
$\mathbf{A}$
$\mathbf{S}$
$\mathbf{E}$

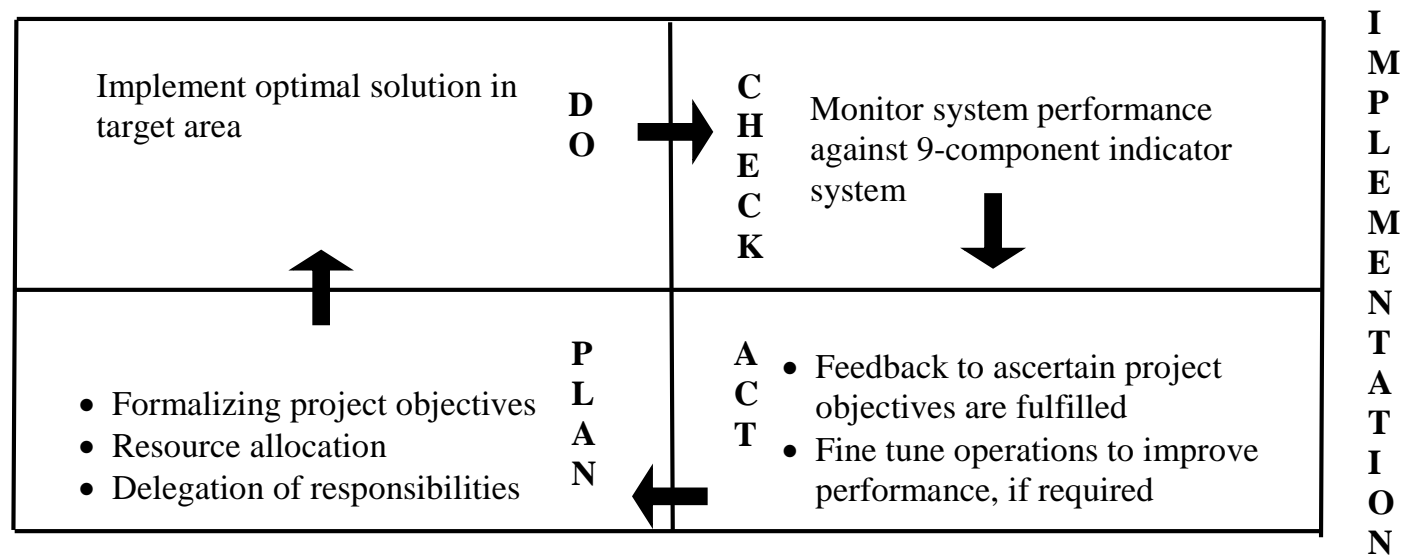

Figure 5: Application of the 9-component Performance Indicator system in PDCA cycle

Accordingly, the cycle can be implemented in two broad stages - planning and implementation. Before the planning stage, impending drivers of change (DoC) and/or prominent concerns affecting the supply system are first identified. For example, in light of climate change the most pertinent issues are changes in raw water quality and quantity. It is also very useful to understand the possible impacts of the DoC on the supply system because this will shape the nature and direction of the policy 
decisions - If the DoC are expected to have a profound impact, the resulting policy will assume high priority. These potential impacts can be evaluated preliminarily by various statistical tools and discussions with specialists.

In the planning stage, after identifying current and potential concerns, target objectives and standards are set based on an in-depth analysis of the impacts of the DoC on the supply system, which can be easily quantified by various mathematical models. Feasible solutions are then explored. For example, a possible solution to countering the affect of degraded raw water quality is to change the treatment technology, if economically feasible, or an ideal way to reduce energy use in an effort to foster climate change mitigation would be to explore the use of clean energy (Plan). Further, numerical models are developed for various scenarios, which integrate the DoC and the operational features of the supply system, along with the potential corrective solutions (Do). For example, to assess the effect of degraded raw water quality, various scenarios of increase in raw water turbidity can be modeled. The removal efficiency with the existing treatment can be calculated and if found wanting, alternate forms of treatment can be explored. The 9-cPIS is, then, used to evaluate these models for the various scenarios (Check). For example, the CSWQ component of the 9-cPIS can be used to ascertain whether or not the modeled solution provides for the required level of finished water quality based on the standards/objectives established earlier in the Plan stage. Similarly, the GWS component is useful to determine how effective the modeled solution is with respect to energy use. Based on how the models perform against the 9-cPIS, an optimal solution is finalized upon, after which an operation period to implement the optimal solution is decided upon (Act).

In the implementation stage, first the project objectives are finalized following which arrangements are made for the necessary finances, infrastructure and personnel (Plan). If the project is large, there will be a number of sectors involved. Hence, delegation of responsibilities to avoid overlap, and effect smooth functioning is essential. The optimal solution finalized in the planning stage is now implemented in a real time situation on, preferably, a small-scale basis (Do). This is to prevent any major disruption in the supply system because of problems arising from some unforeseen issues. The system is then monitored against the 9-cPIS to check how well the modeled solutions perform in real time (Check). Actual data is collected for the required variables of the 9-cPIS over a fixed duration, after which the magnitudes of the component of the 9-cPIS can be mathematically estimated. Depending on the system response, against the 9-cPIS, if required, further fine-tuning of the system is explored and modifications and revamping of the supply system are proposed (Act). 


\section{Conclusion}

The objective of this study was to revise the existing PI system for water utilities in Japan to arrive at a reduced, relevant and practical structure that accounts for enough information required to rationally evaluate small water supply systems. Using Principal Component Analysis the dimensionality of the existing PI data set consisting of 137 items was reduced to 9 components consisting of 33 items (9cPIS), while at the same time retaining $64.9 \%$ variation of the original data set. The indicator system addresses both current and future concerns for small water supply utilities in Japan. Current concerns include decreasing population trend, diminishing financial returns, customer satisfaction etc. which are evaluated by Employee Productivity, Economic Value of Water, Financial Sustainability, Private Investment, Consumer Satisfaction for Water Quality and Earthquake Resistant Water Supply, while the future concerns about climate change and disaster management are evaluated by Adaptive Management, Green Water Supply, Emergency Response Index. The 9-cPIS while comparable to the PI systems developed by other international agencies like the IWA and IBNET, yet address issues that are specific in the Japanese water supply context. The study provides a generalized methodology for arriving at a reduced set of pertinent PIs in the water industry, which can be a guideline for other countries, which currently employ a large number of PIs. Additionally, the study presents the potential application of the 9-cPIS in benchmarking, business modeling and the PDCA cycle for small water utilities in Japan.

It must be mentioned that the key PIs developed in this study are not an exhaustive list but are primarily meant for small utilities in Japan, derived from an existing set of indicators using a dimension reduction technique. Hence, there may be some relevant variables for which data is currently not available or which are likely to impact water supply systems in future could not be included in the study. Further research could include refining the 9-cPIS by including these variables as proxies. By providing the small utilities with a reduced set of relevant indicators, the study can make a significant contribution in the planning and management of the water supply, and the utilities can make informed and rational decisions to ensure the sustainable supply of safe and good quality water in Japan.

\section{References}

ADB, 1997. Guidelines for Economic Analysis of Projects. Economic and Development Resource Center, Asian Development Bank Publications. Retrieved July 2011 from website http://www.adb.org/Documents/Guidelines/Eco_Analysis/financial_sustainability.asp 
Alegre, H., 2002. Performance indicators as management support tool. In Mays L.W. (Eds.), Urban Water Supply Handbook. New York: McGraw-Hill.

Alegre, H., Baptista, J.M., Cabrera Jr, E., Cubillo, F., Duarte, P., Hirner, W., Merkel, W. and Parena, R., 2006. Performance indicators for Water Supply Services - Second Edition. Manual of Best Practice Series, London, IWA Publishing.

Barrett, P. T., \& Kline. P., 1981. The observation to variable ratio in factor analysis. Personality Study and Group Behavior, 1, 23-33.

Bates, B.C., Kundzewicz, Z.W., Wu, S. and Palutikof, J.P., Eds., 2008. Climate change and Water: Technical Paper of the Intergovermental Panel on Climate Change, IPCC Secretariat, Geneva, $210 \mathrm{pp}$.

BDEW, 2010. Report on Benchmarking: "Learning from the best”, Comparison of performance indicators in German water industry.

Blokland, M.W. 2010. Benchmarking water service delivery. In Kurian, M. and McCarney, P. (Eds.), Peri-Urban water and sanitation services: Policy planning and method. Heidelberg, Germany, Springer.

Chang, N., Pongsanone, P. and Ernest, A. 2012. A rule-based decision support system for sensor deployement in small drinking water networks. Journal of Cleaner Production, Vol 29-30, 2837.

Costello, A.B. and Osborne J., 2005. Best practices in exploratory factor analysis: four recommendations for getting the most from your analysis. Practical Assessment Research \& Evaluation 10(7). Available online: http://pareonline.net/getvn.asp?v=10\&n=7

Coulibaly, H.D. and Rodriguez, M.J., 2004. Development of performance indicators for small Quebec drinking water utilities. Journal of Environmental Management, 73, 243-255.

Deming, W.E., 1986. Out of the crisis. MIT, Center for advanced educational studies.

Duong, T.T.H., Adin A., Jackman, D., van der Steen P. and Vairavamoorthy, K., 2011. Urban water management strategies based on a total urban water cycle model and energy aspects - Case study for Tel Aviv. Urban Water Journal, 8(2), 103-118.

Gregory, R., Failing, L. and Higgins, P., 2006. Adaptive Management and Environmental Decision Making: A case study application to water use planning. Ecological economics, 58(2), 434-427.

Gorsuch, R.L., 1983. Factor analysis. 2nd edition. Lawrence Erlbaum Associates, Inc., New Jersey, Hillsdale.

IBNET, 2005. International Benchmarking Network for Water and Sanitation Utilities. Retrieved July, 2011 from website http://www.ib-net.org/en/texts.php?folder_id=100\&L=1\&S=2

Ioris, A.A.R., Hunter, C. and Walker, S., 2008. The development and application of water management sustainability indicators in Brazil and Scotland. Journal of Environmental Management 88, 1190-1201.

Itoh, S., Hirayama, N., Kagawa, K. and Shiro, S., 2006. Development of an Information Disclosure Technique for Reducing Citizens' Concern on Tap Water Quality. Advances in Asian Environmental Engineering, 5(1), 31-38.

Itoh, S., Shiro, S., Hirayama, N., Echigo, S. and Ohkouchi, Y. 2007. Psychosocial considerations on strategies for improving customers' satisfaction with tap water based on casual modeling. Journal of Japan Water Works Association, 76(4), 25-37

Jolliffe, I.T., 2002. Principal Component Analysis, Second edition. Springer series in statistics. New York, Springer-Verlag.

JWWA, 2005. Guidelines for the management and assessment of drinking water services. Japan Water Works Association.

JWWA, 2008. Japan Water Supply Data Report. Japan Water Works Association

Kaplan, R.S. \& Norton D.P. (1992). The balanced score card: Measures that drive performance. Harvard Business Review, 70 (1), 71-79. 
Kaiser, H.F., 1960. The application of electronic computers to factor analysis. Educational and Psychological Measurement, 20, 141-151.

Kanakoudis, V. and Tsitsifli, S., 2010. Results of an urban water distribution network performance evaluation attempt in Greece. Urban Water Journal, 7(5), 267-285.

Kline, P., 1994. An easy guide to factor analysis. London, Routledge..

Kline, P., 1979. Psychometrics and Psychology. London, Academic Press.

Kaneko, R., Ishikawa, A., Ishii, F., Sasaki, T., Iwasawa, M. and Morizumi, R., 2007. Population projection for Japan 2006-2055: with long-range population projection: 2056-2105. Journal of Population Problems, 63(1) 260, 29-71 (In Japanese)

MacCallum, R. C., Widaman, K. F., Zhang, S., \& Hong S., 1999. Sample size in factor analysis. Psychological Methods, 4, 84-99.

Makungo, R., Odiyo, J.O. and Tshidzumba, N., 2011. Performance of small water treatment plants: The case study of Mutshedzi water treatment plant. Physics and Chemistry of the Earth, 11511158

Milman, A., and Short, A., 2008. "Incorporating Resilience into Sustainability Indicators: An Example for the Urban Water Sector." Global Environmental Change, 18(4), 758-767.

MLITT, 2008. Water Resources in Japan. Ministry of Land, Infrastructure, Transport and Tourism, Retrieved July, 2010 from website http:/www.mlit.go.jp/tochimizushigen/mizsei/water_resources/index.html

OECD, 2010. Pricing Water Resources and Water and Sanitation Services, OECD Studies on Water, OECD Publishing. doi: 10.1787/9789264083608-en

Oki, T. and Musaike, K., 2009. Time for a change in Japanese Water Resources Policy, Part 3: National and Institutional Directions. Water Resources Development, 25(4), 571-578

Osterwalder, A. and Pigneur, Y., 2010. Business Model Generation: A handbook for visionaries, game changers and challengers, New Jersey, John Wiley and Sons.

Palme, U. and Tillman, A.M., 2008. Sustainable development indicators: how are they used in Swedish water utilities? Journal of Cleaner Production, 16, 1346-1357

Ravindran, V., Tsai, H., Williams, M.D. and Pirbazari, M. 2009. Hybrid membrane bioreactor technology for small water treatment utilities: Process evaluation and primordial considerations. Journal of Membrane Science, 344(1-2), 39-54.

Sadiq, R., Rodriguez, M.J. and Tesfamariam, S., 2010. Integrating indicators for performance assessment of small water utilities using weighted averaging (OWA) operators. Expert Systems with Applications, 37, 4881-4891

Schwartz, K. and Sanga, A. 2010. Partnerships between utilites and small-scale providers: Delegated management in Kisumu, Kenya. Physics and Chemistry of the Earth, Parts A/B/C, 35(13-14), 765-771.

Tachikawa, H., 2004. Key note speech: A few hot issues of water supply in Japan. Health Service Bureau, Ministry of Health, Labor and Welfare. Retrieved Sep, 2010 from website www.niph.go.jp/soshiki/suido/pdf/h19JPUS/abstract/a01.pdf

Tabachnick, B. G., \& Fidell, L. S., 2001. Using Multivariate Statistics, Boston, Allyn and Bacon.

Tynan, N. \& Kingdom, B. (2005). Optimal size for utilities. Returns to scale in water: evidence from benchmarking. Public Policy for the Private Sector, Note No. 283. Washington, DC: World Bank.

UNCED, 1992. United Nations Conference on Environmental Development, Rio de Janeiro, June 1992

USEPA-DWA, 2003. An Overview of the Safe Drinking Water Act. US Environmental Protection Agency-Drinking Water.

Water UK, 2010. Sustainability indicators 2009-2010. Retrieved Aug 2011 from website http://www.water.org.uk/home/policy/publications/archive/sustainability/2009-10-report 
WHO, 2000. Tools for Assessing the Operation and Maintenance Status of Water Supply and Sanitation in Developing Countries. Geneva: World Health Organization

World Bank, 1999. Benchmarking Water \& Sanitation Utilities: A Start-Up Kit. Transportation, Water and Urban Development Department, Water and Sanitation Division, The World Bank, Wasinngton D.C.

Young, R.A., 2005. Determining the economic value of water: concepts and methods. Resources for the Future Publications, Washington D.C.

Velicer, W. F., \& Fava, J. L., 1998. Effects of variable and subject sampling on factor pattern recovery. Psychological Methods, 3, 231-251.

VEWIN. (2007). Reflections on performance 2006. The Netherlands: VEWIN

Zaag, P., and Savenije,H.H.G., 2006. Water as an economic good: The value of pricing and the failure of markets. Value of water research report series no. 19. UNESCO-IHE Institute for Water Education, Delft, the Netherlands. 